\title{
RELIABILITY-BASED ASSESSMENT OF MASONRY ARCH BRIDGES
}

\author{
Joan R. Casas \\ School of Civil Engineering. Universitat Politècnica de Catalunya (UPC) \\ C/Jordi Girona 1-3, 08034- Barcelona, SPAIN \\ e-mail:joan.ramon.casas@upc.edu \\ Phone: 34-934016513, FAX: 34-934054135
}

\begin{abstract}
The paper presents a methodology for the probabilistic assessment of masonry arches at the serviceability and ultimate limit states. First, it explains the definition of the different failure modes and corresponding limit state functions that may occur depending on the type of masonry construction (single-ring and multi-ring). The most reported modes of failure are the four-hinge mechanism, the ring separation in multiring arches and the slippage at the foundations. Because of the lack of reliable material data (in the statistic sense) or available response models, only those more prone to be analyzed using reliability-based methods are shown in this paper: four-hinge mechanism and ring separation.

The possibility of fatigue failure of masonry arch bridges under service loads and the proposal of reliability-based assessment methods at the ultimate level of the 4 hingemechanism are also analyzed. Finally, the proposed methodology is applied to an existing bridge.
\end{abstract}

Keywords: masonry, arch, reliability, fatigue, serviceability

\section{1.- Introduction}

Over the past 10 years there has been an extensive programme of research which considered some aspects of masonry arch behaviour. A number of small and large scale tests have been carried out on masonry arches, most of them have been under static (monotonic) loading and considered mainly the arch ring itself. However, there has been very little work done on investigating the long-term effect of traffic (cyclic) loading and the effect of deteriorated masonry on the fatigue life of the bridge.

Several semi-empirical and numerical methods exist to determine the load carrying capacity of masonry arches: MEXE method, maximum stress analysis, limit analysis (mechanism) methods [1,2,3], solid mechanics methods (Castigliano's non-linear analysis, finite element analysis, discrete element analysis). Many computer-based applications of these methods also exist ( Archie-M, RING, DIANA....). Recently, the possibility of fatigue failure under cyclic loading at normal service level of loading, much lower than the ultimate load [4] has suggested a new approach to the assessment of masonry arches based upon the long-term performance of masonry subjected to cyclic loading [5,6]. Available assessment methods of masonry arches are deterministic 
in nature. They can predict ultimate capacity provided that all variables involved in the response are assumed as deterministic values, what is not really the case due to uncertainties involved in geometry, materials and loads.

Reliability-based assessment of structures and particularly bridges has been successfully implemented and performed in recent years. These methods assume the intrinsic uncertainty of the variables involved. Most of the experiences have been done in the field of bridges either from structural concrete (reinforced and prestressed) or steel. Several experiences have shown the large amount of money that can be saved by an efficient and accurate assessment based on a probabilistic approach [7-12]. However the application to masonry bridges has been almost negligible. One reason is the difficulty to define reliable failure criteria for this type of structures. Another reason is the lack of statistical data on material properties of masonry and filling material. The experimental tests show that normally the failure of an arch is of a global nature more than due to the failure of a bridge component. In most cases, even the division of the bridge in different components is almost impossible. For this reason, also the lack of accurate theoretical models for the idealization of the behaviour of the masonry arch bridge as a system, including the interaction effects with the filling material, spandrel walls, etc., has been another difficulty not yet overcome. Last, but not least, the absence of reliable data on the statistical definition of the material properties has been another issue that has limited the use of probability-based assessment techniques. Very few data is available for the behaviour of the masonry under static loads. The lack of experimental data is even more dramatic in the case of cyclic loading. Estimation of masonry strength from measurements may then be one of key issues of the assessment of existing structures $[13,14]$.

However, some experiences have shown the potentiality of the use of reliability-based assessment in the capacity assessment of masonry structures in bending and compression [15-18]. As an example, in [19] the structural reliability of typical reinforced grouted concrete block masonry walls designed to Chinese standards is evaluated.

In the particular case of masonry arches, few cases of application of probabilistic assessment together with accurate models of the bridge behaviour are available. In [20], the reliability analysis jointly with non-linear models of a masonry arch bridge using implicit limit state functions is presented. A method for the sensitivity analysis is also proposed. In some cases, masonry bridges that will be rated as unsafe when using standard methods of assessment and linear models, have reported high enough level of safety when appropriate theoretical models and probabilistic assessment tools are applied [21]. The available models have focussed in the failure mode of masonry under compression. However, as presented in this paper other failure modes as fatigue under serviceability loads have to be considered. The present paper describes the background and methodology for a reliability-based assessment taking into account several failure modes including fatigue.

\section{2.- Failure modes in masonry arches}

The first step in a reliability-based assessment of masonry arch bridges requires the identification of the failure modes and the definition of their limit state functions. A 
complete description of failure modes in masonry arch bridges can be found in [4]. As seen there, it is usually assumed for a single square spanned bridge that the failure mechanism involves the formation of 4 hinges. However, there are other failure possibilities as the formation of 3 hinges plus the horizontal displacement of the abutment, the crushing of the masonry, the ring separation in multi-ring arches due to the failure of the mortar between rings, punching shear failure as a result of failure of the radial mortar joints, foundation failure because of scour, failure of the backfill, among others. In summary, the most reported modes of failure are the four-hinge mechanism, the ring separation in multi-ring arches and the slippage at the foundations [4]. Because of the lack of reliable material data (in the statistic sense) or available response models, only those more prone to be analyzed using reliability-based methods are shown in this paper: four-hinge mechanism and ring separation. This is also based in the fact that they are structural modes of failure. The foundation failure mode can be addressed by a separate study where emphasis should be directed to the geotechnical aspects of the arch response. Basically, the most likely failure mode will depend on the type of construction used for the arch. For this reason, a separation is made between single and multi-ring arches. Also, a different failure mode could appear in the case of static or cyclic loading. Generally, single-ring arches loaded statically are more prone to a failure by four-hinge mechanism, whereas ring separation is the main failure mode in multi-ring arches submitted to cyclic loading. This is further explained in the following subchapters.

\section{1.- Single ring arches}

In the case of an unique ring, either made of a single masonry or of several interrelated units of masonry ( see figure 1), the most likely failure mode is due to the formation of a four-hinge mechanism because of an extreme load [22]. The mechanism normally appears before any separation between units or crushing of the material occurs. This type of failure should be considered as an Ultimate Limit State (ULS). However, the degradation and loss of structural integrity due to ageing, may affect the ability of the material to carry the normal service loads for the expected life of the bridge. In this case, the resulting limit state is considered as a Serviceability Limit State (SLS) or also a so-called Permissible Limit State (PLS) $[4,5,6]$, in the sense that even not reaching the maximum allowable load for a unique application, the bridge may fail due to repeated application of lower levels of loading. In this case, the attempt is to determine the residual life taking into account the normal loads in the bridge and looking to its longterm performance, similar to a fatigue check. Despite being less feasible, the fatigue failure has to be also considered in this type of arches, mainly when deterioration due to aging and service loads may derive on lower fatigue strength of the ma sonry mix. The fatigue failure is due to repeated cycles of compression causing the crushing and squeezing of the mortar from the mortar joints followed by vertical splitting of the bricks. 


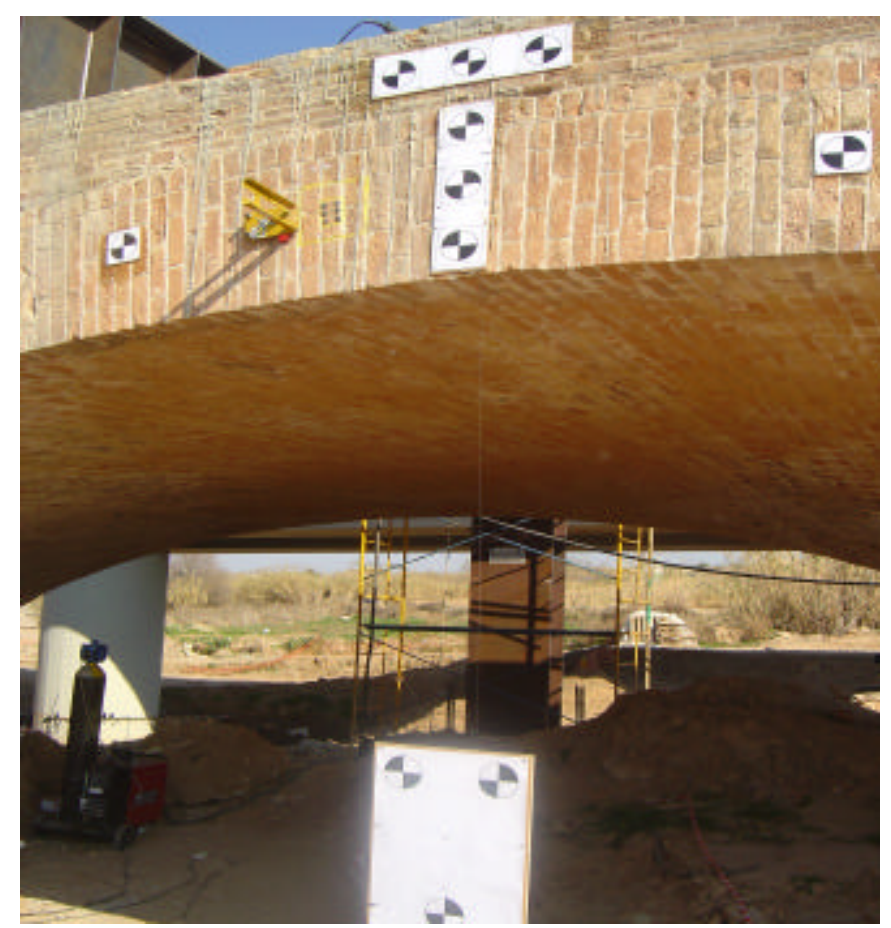

Figure 1.- Single ring arch formed by several units across the arch barrel depth

\section{2.- Multi-ring arches}

In the case of a multi-ring arch, the failure could be either by the formation of the fourhinge mechanism (figure 2) or by ring separation (figure 3). The failure by one or other mechanism will depend on the specific characteristics of the bridge: span-length, span to raise ratio, type of mortar between rings and also the loading type: static or dynamic.

The four-hinge mechanism is similar to the case of a single arch and again the failure should be analyzed as an ULS. In a multi-ring masonry arch, normally this mechanism appears in the case of monotonic loading conditions.

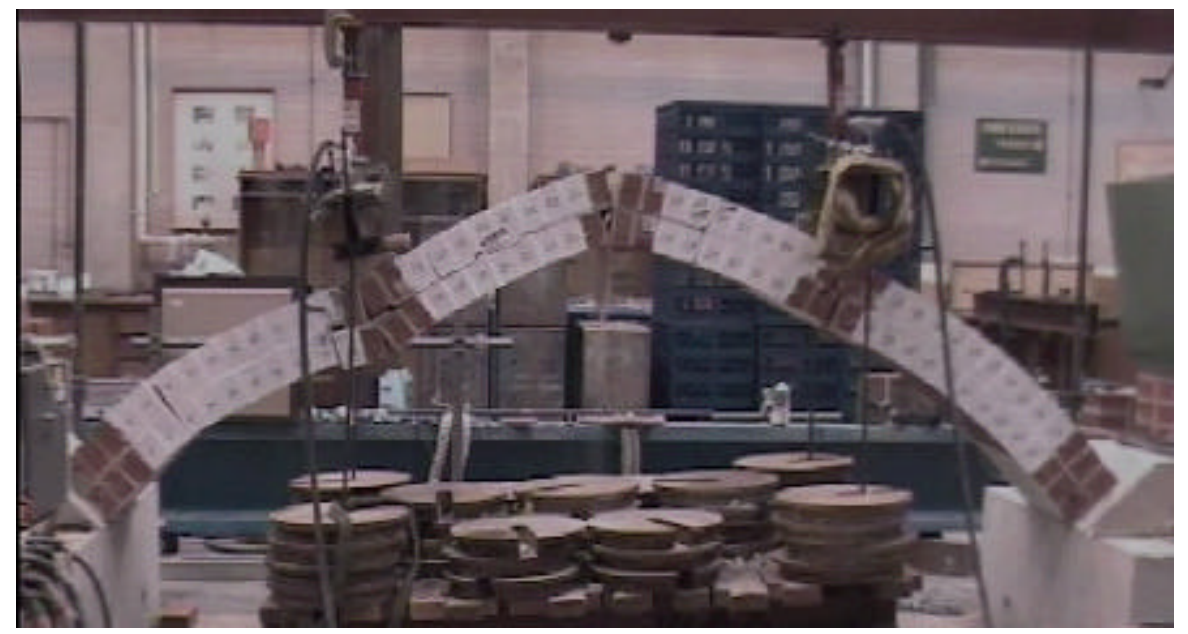

Figure 2.- 4 hinges mechanism of failure of a multi-ring arch. Test carried out at the University of Salford (UK) [4] 
The failure mechanism by ring separation normally appears under cyclic loading conditions, although also a monotonic extreme load may cause the separation. In the case of static loading, ring separation can occur between the $1 / 4$ point and the nearest abutment and the failure is considered as an Ultimate Limit State. For cyclic loading, the separation occurs between the $1 / 4$ and $3 / 4$ point. In the case of the ring separation under cyclic loading, the failure should be considered a Fatigue Limit State, or, again, as a Permissible Limit State $[4,6]$.

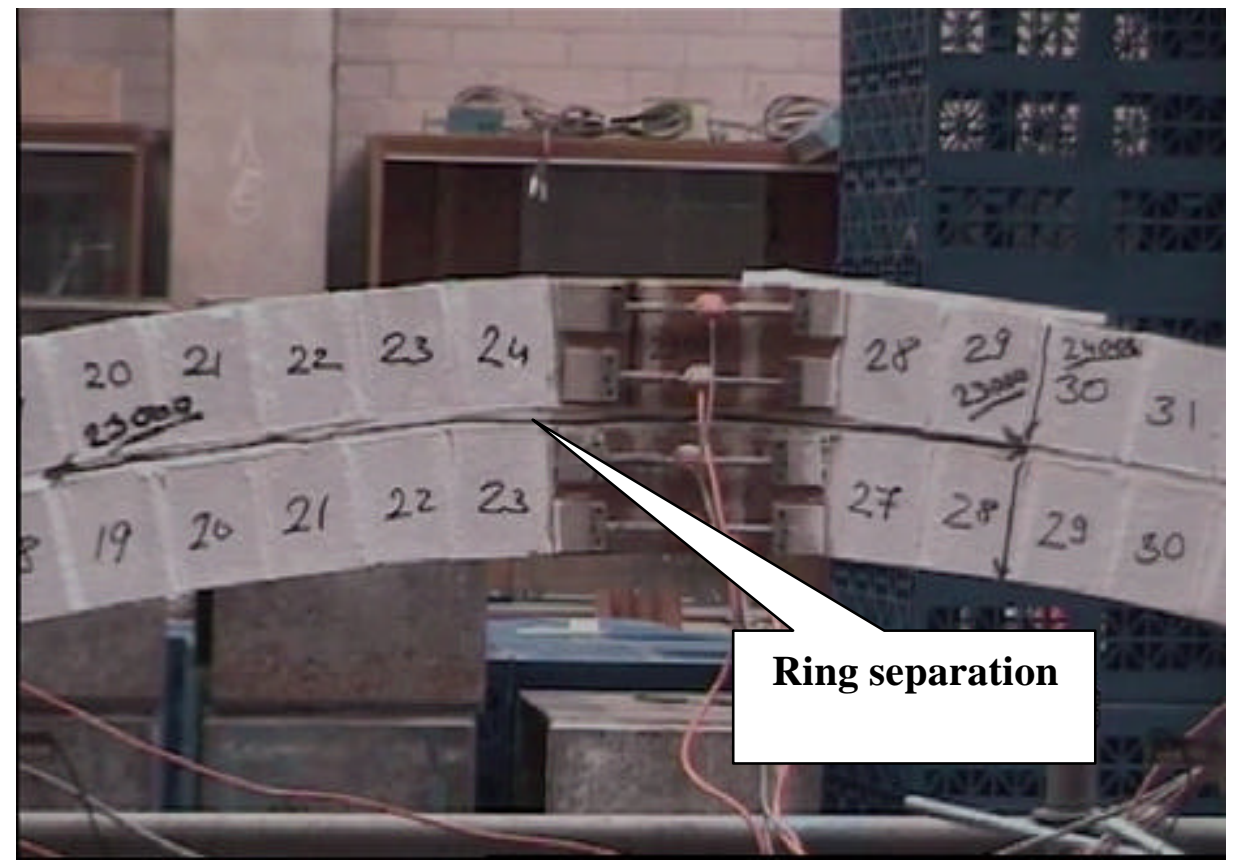

Figure 3.- Failure by ring separation in a multi-ring arch. Test carried out at the University of Salford (UK) [4]

\section{3.- Limit State functions}

Depending on the criteria adopted to define the failure of the bridge, different limit state functions and different levels of assessment can be formulated. According to the failure mechanisms defined in chapter 2, the possible levels of assessment and corresponding Limit State functions are described below. Despite a significant uncertainty exists on the ability of the used models to characterize the behaviour of masonry structures, even for the most advanced ones, model uncertainty has not been considered explicitly in the definition of the Limit State functions. The mean reason is that, at the present moment, not sufficient experimental data is available to statistically define such uncertainty. It is clear that this should be corrected as more comparisons between experimental and numeric al results will become available. Neglecting the model uncertainty in the Limit State function can be compensated by requiring a higher target reliability level in the structure than in the case where model uncertainty is considered.

At least, 3 assessment levels exist, with increasing level of complexity and accuracy depending on the failure criteria and analytical model used. They are summarized in the diagram in figure 4 jointly with the failure modes and limit states considered, and fully described below. 


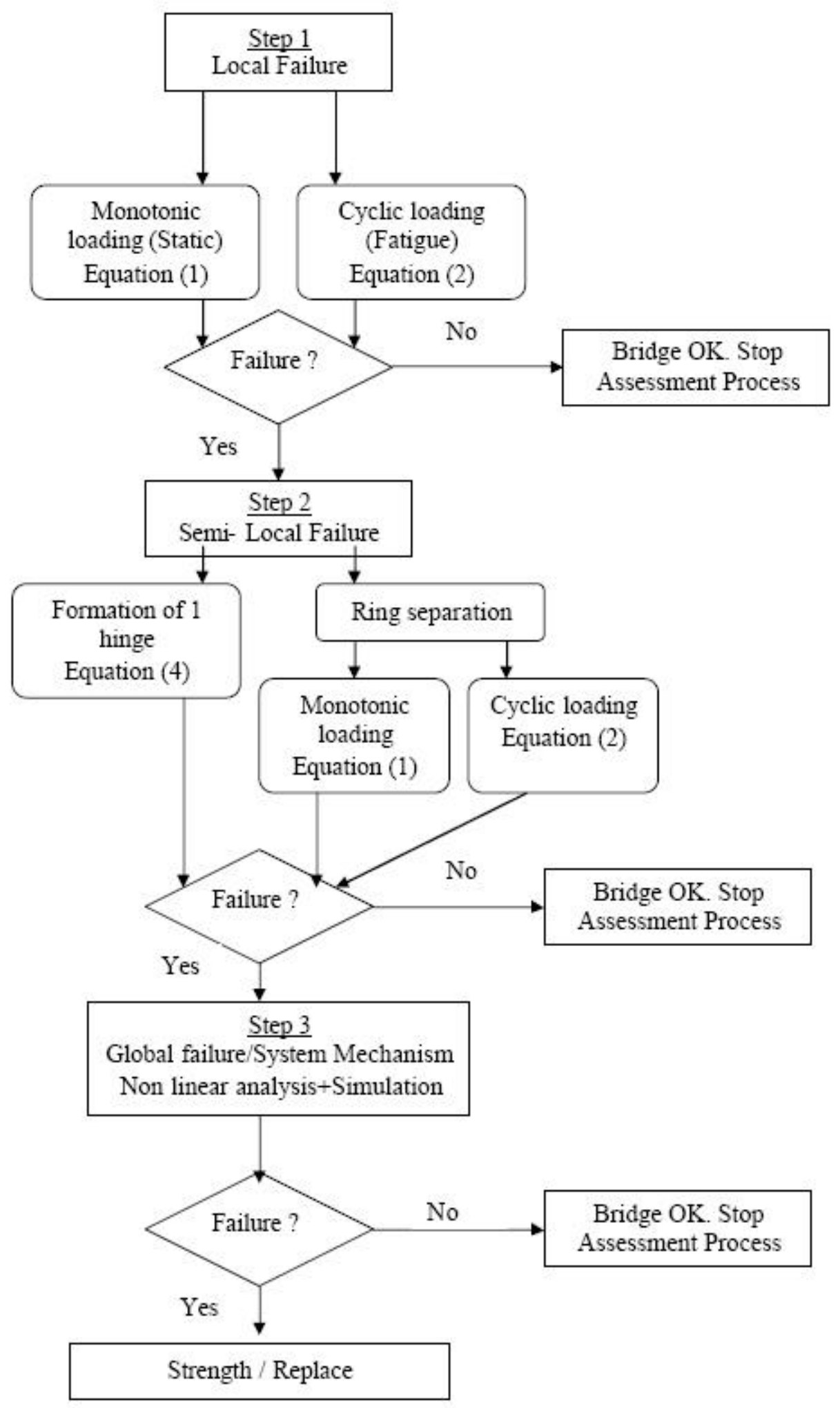

Figure 4.- Summary of the proposed assessment process 


\section{1.- First level of assessment: local failure}

\subsection{1.- Monotonic loading}

This failure occurs when an extreme load causes excessive bending moments/shear forces combined with important axial loads resulting in the failure either because tension stress appears or excessive compression in the material provokes crushing of the masonry. The failure criteria can be based on the Ultimate Limit State (ULS) formulation. The lowest capacity level will be obtained considering the failure of the bridge when any fibre at any cross-section is in tension or it reaches the maximum allowable compression of the material. The corresponding LS function is:

$$
\begin{gathered}
G=\sigma_{\text {min }} \\
G=f_{c}-\sigma_{\text {max }}
\end{gathered}
$$

where $\mathbf{s}_{\min }$ and $\mathrm{s}_{\max }$ are the lowest and highest stress at any point of the bridge and $f_{c}$ is the compressive strength of masonry. The value of the internal forces (bending moment, normal force) and the distribution of stresses in the cross-section are derived assuming a linear behaviour of the structure and the material. Of course, this is an extremely restrictive and over-conservative failure criterion. However, if the bridge passes this level of assessment, that requires very simple modelling tools, it may be assured that the bridge is in very good shape.

\subsection{2.- Cyclic loading (fatigue)}

The few available high cycle fatigue tests either in small specimens [23] or full laboratory models [4] have shown that the fatigue strength of brick masonry subject to compressive-bending state depends upon the induced stress range, the mean or maximum induced stress and the quasi-static compressive strength of the masonry under similar loading conditions.

Considering that a set of experimental points in the $\mathrm{S}-\mathrm{N}$ plane is provided, then the fatigue capacity from a probabilistic point of view can be analysed in a similar way as in the case of concrete or steel [24]. The Limit State function in the case of several number of cycles of different load intensity, assuming that Miner's rule is of application [6], can be written in the following way:

$G=1-\sum_{\Delta \sigma_{i}} \frac{n_{i}}{N_{i}}$

$\mathrm{n}_{\mathrm{i}}=$ number of cycles of load level $? \mathrm{~s}_{\mathrm{i}}$ due to external loads (random variable)

$\mathrm{N}_{\mathrm{i}}=$ number of cycles of load level ? $\mathrm{s}_{\mathrm{i}}$ that the bridge can support (random variable)

$\mathrm{n}_{\mathrm{i}}$ as a random variable will be obtained via a structural analysis taking into account the randomness in the live-loads acting on the bridge or, alternatively, by extrapolation of measurements taken in the bridge. Also the variability of the bridge properties should be considered in the definition of $n_{i}$ as the stress increment will also depend on these properties. 
At the present stage and despite some preliminary tests [6], there is not yet a clear evidence that the Miner's rule is applicable to masonry material as it seems to be for steel. In this sense, there is still a limitation for a fully appraisal of the results obtained by the application of the proposed assessment method.

The way to derive the statistics of random variable $n_{i}$ is by simulation of traffic effects jointly with simulation of geometric and material properties of the structure [24,25]. In the case of railway traffic and taking into account that the stress increments due to bridge dynamics will be very low for this type of bridges ( the infill mitigates the vibration level), one may consider the passage of each convoy as a cycle of loading.

The statistical definition of $\mathrm{N}_{\mathrm{i}}$ can be done in the following way. Different works have shown that the Weibull distribution function agrees very well with the expected physical criteria of progressive fatigue deterioration [26,27]. On the basis of physically valid assumption, sound experimental verification, relative ease in its use and better developed statistics, the Weibull distribution has been widely used for the fatigue analysis of metals. It is also well-suited for certain procedures of statistical extrapolation of large systems [26]. In [27] and [28], the distribution of fatigue life of concrete was found also to approximately follow the Weibull distribution. Some theoretical and experimental works $[29,30]$ have shown also the feasibility of the Weibull distribution regarding the statistical model for steel wires and strands to fatigue.

The expression for the Cumulative Distribution Function (CDF), $\mathrm{F}_{\mathrm{N}}(\mathrm{n})$, of a Weibull random variable is:

$F_{N}(n)=1-\exp \left[-\left(\frac{n-n_{0}}{u-n_{0}}\right)^{\alpha}\right], n \geq n_{0}$

being $\mathrm{a}=$ shape parameter, $\mathrm{u}=$ characteristic extreme value and $\mathrm{n}_{0}=$ minimum value.

For fatigue analysis, $\mathrm{n}_{0}$ is usually taken equal to $0.0[26,27]$.

A complete definition of the fatigue strength in probabilistic terms requires the knowledge of parameters a and $\mathrm{u}$ for all possible stress levels. This is not the case in most situations because of lack of experimental data. It has been demonstrated that a Weibull distribution for the fatigue strength of masonry and for several stress levels can be derived based on the experimental data available at the present time [31]. From the few tests in small scale arches reported so far it seems than the S-N curve has only one branch [31]. This is different from the case of steel where several branches with different slopes have been reported [24].

\section{2.- Second level of assessment: semi-local failure}

\subsection{1.- Hinge formation}

If the bridge does not pass the first level of assessment, then the next level is applied. In this case, regarding the combined axial-bending action, the failure mechanism occurs when the compression block in the masonry ( being the value of the compression equal to the compressive strength of the masonry) is not able to balance the normal load (N) and bending moment (M) due to the external actions. Failure is reached when any crosssection fails. In essence, this failure criterion is equivalent to the formation of an hinge in only one cross-section of the bridge. For this reason, it is under the label of semi- 
local failure as the formation of only one hinge may not mean the failure of the whole arch. The internal forces $\mathrm{N}$ and $\mathrm{M}$ are obtained with a linear-elastic model of the arch. The Limit State Function can be formulated in the following way:

$$
G=H-\frac{N}{f_{c} B}-\frac{2 M}{N}
$$

$\mathrm{H}$ is the cross-section depth, $\mathrm{B}$ is the cross-section width, $\mathrm{f}_{\mathrm{e}}$ is the compressive strength of masonry. In chapter 5, an example with a practical application of this method is shown.

\subsection{2.- Ring separation}

The failure mode by ring separation in multi-ring arches can be also included in this category. Ring separation in multi-ring masonry arches may occur either by an increasing monotonic load (Ultimate LS) or by the repetition of a great number of cyclic loads (Fatigue LS). In both cases the failure is due to the rup ture of the mortar between the rings due to the shear stresses. From the point of view of the analysis, two cases are of consideration as has been reported in several tests [4]:

1.- The arch fails by ring separation independently of the number of cycles of load. In this case, only one failure mode is of consideration and the limit state of fatigue as described in 3.1.2 can be used to predict the bridge capacity. The case of several number of cycles of load with different level could be approached by using the Miner's rule (equation 2) as only one mechanism of damage provoking the ring separation is present in this case.

2.- The arch may develop two failure mechanisms. For a reduced number of cycles of load, the failure is by four-hinge mechanism(see 3.3) with a load level close to the static failure load, and for a high number of cycles with lower load, failure happens due to ring separation. In this case, two failure modes are coupled. The S-N diagram could be still derived, with two branches, each one modelling one failure mode as seen in figure 5. Figure 5-a shows the case where for a low number of cycles of very high load, the arch fails by the 4-hinge mechanism, up to a certain number of cycles of load $\left(\mathrm{N}^{*}\right)$ where the critical mechanism becomes the ring separation. In this case, depending on the compression stress level, the failure is either by the formation of the mechanism or by the ring separation. In the case of figure 5-b, there is a range of compression stresses where the failure can be both by mechanism or ring separation depending on the shear stress level induced by the load configuration in the joints of the ring. However, the use of Miner's rule could be debatable in this case. In fact, the accumulation of damage is not of application if damage is caused by different mechanisms. Only the damage caused by the same mechanism of failure can be accumulated. On the other hand, one external load produces some damage in both mechanisms. 


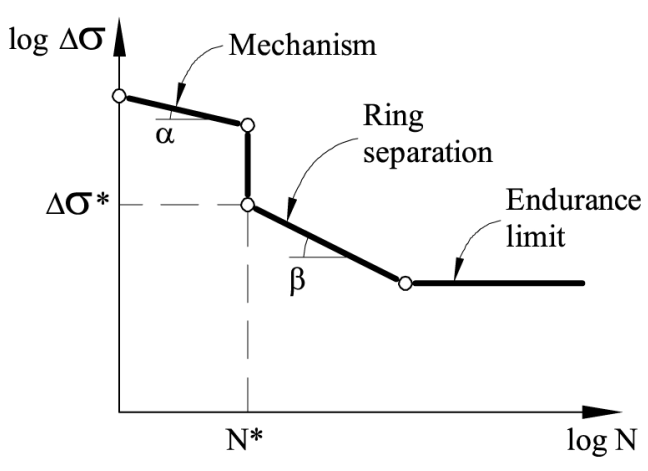

(a)

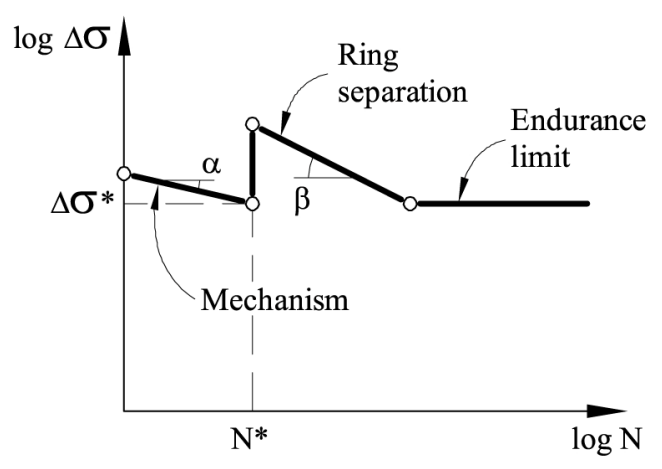

(b)

Figure 5.- S-N curves for the coupled "mechanism-ring separation" fatigue behaviour

This approach based on the definition of S-N curves for the whole arch derives on an unpractical methodology. In fact, the shape of the S-N curve in the case of the bridge (system level) will depend on the specific characteristics of the bridge, with its particular configuration of geometry, boundary conditions and loading pattern. Depending on those parameters (among others), the fatigue effects due to the hinged mechanism or the ring separation will be more or less enhanced. In fact, the level of the normal or shear stresses governing both mechanisms depend on the mentioned variables. As a consequence, the $\mathrm{S}-\mathrm{N}$ curve obtained in a fatigue test will be only representative of the specific conditions of such test, and could be hardly adopted in the case of a bridge with other cond itions. For this reason, the approach based on the definition of S-N curves at a local or material level (see 3.1.2) and not at the arch level will be adopted as presented in [31]. In this case, the derivation of the $\mathrm{S}-\mathrm{N}$ curves become also simpler as the fatigue tests may be carried in small specimens and not in the whole arch structure.

\section{3.- Third level of assessment: global failure (system mechanism)}

In this case, the bridge is considered to fail when a sufficient number of plastic hinges (normally 4) develop in different cross-sections to form a global/system failure mechanism. The failure can be due to either the development of a mechanism or the incapacity to accommodate further deformations without breaking the material. To take into consideration the behaviour up to failure of the bridge, more sophisticated theoretical models are necessary that take into account both material and geometrical non-linearities. A complete summary of the available numerical and analytical models to analyze the four-hinge failure mechanism is reported in [4]. These numerical models are able to simulate the formation of the hinges in the critical sections. The application of probability-based assessment methods when using such sophisticated and advanced models is cumbersome. Because of the non-linear nature of the problem, an explicit Limit State equation is not available. The approach is to use a simulation process for the calculation of the probability of failure. However, crude Monte-Carlo simulation can be hardly applied due to the huge number of runs necessary in the non-linear model and the complexity of such a model. For this reason more advanced simulation techniques as the importance-sampling, directional sampling and Latin Hypercube Method or other alternative methods as the Surface Response method [32] are the most adequate tools to combine with a full non-linear model. In the example in chapter 5 is presented a practical application using the Latin Hypercube Method. 


\section{4.- Definition of basic variables}

A second step in the probabilistic approach to the assessment of masonry arches requires the statistical definition of the basic variables involved. The statistical definition of the basic variables should be based on the available data existing in the literature up-dated with the measurements obtained directly on the bridge under assessment. The most important data that needs to be collected in order to improve the quality of the predicted carrying capacity using probabilistic techniques is shown in the following.

\section{1.- Dimensions}

The most representative dimensions for a probabilistic analysis of masonry arches are the arch thickness, arch width, depth of fill at crown, rise at mid-span and span-length. At this time, there is not enough experimental data available to obtain the statistical definition of these variables and in the literature information how to get the statistical parameters is not available too. Based on some measurements made by the author in several masonry arch bridges, a rough estimate of $10 \%$ coefficient of variation for the arch thickness and $5 \%$ for the arch width can be assumed. The distribution function can be assumed as Normal. Because these values have been obtained from a very limited number of samples, it is recommended that up-dating of this information should be done from results gathered in the specific bridge under assessment.

\section{2.- Materials}

The most representative material properties for a probabilistic assessment of a masonry arch are the compressive strength of masonry, tensile strength of masonry, compressive strength and modulus of elasticity of filling material, , density of masonry and filling material, endurance limit to fatigue of masonry and shear strength (interface masonrymortar). At the present time there is very few available data in the literature on the statistical distribution and parameters of these properties and therefore the most appropriate is to gather the data from the specific bridge or structure under assessment.

\section{3.- S-N diagrams. Probabilistic fatigue models}

As previously explained, fatigue failure may occur either under the combined compression-bending action (as in the case of single ring arches) or because of the shear action in the interface unit-mortar (case of multi-ring arches). Because the two mechanisms can be of different origin, a separation is made between them and the corresponding S-N curves for fatigue in each case is presented.

\subsection{1- S-N diagrams for masonry in compression-bending}

As mentioned before, the complete definition of the fatigue strength in probabilistic terms requires the knowledge of the two parameters of the Weibull distrib ution for all possible stress levels. In [31] is explained the derivation of a set of Weibull distributions according to the stress level based on the experimental data today available from brick masonry tests.

According to the results reported in [28], where they propose a probabilistic fatigue model for plain concrete, the following fatigue formula is proposed to take into account the minimum value of repeated stress:

$\log S=\log \frac{\sigma_{\max }}{\sigma_{u}}=1-b(1-R) \log N$ 
$\mathrm{S}$ is the ratio of the maximum loading stress to the strength and $\mathrm{R}$ is the ratio of the minimum stress to the maximum stress $s_{\min } / s_{\max }$. In order to work with only one stress variable instead of two, the introduction of the equivalent fatigue life EN is done. EN is defined as $\mathrm{EN}=\mathrm{N}^{(1-\mathrm{R})}$. In this way, equation (5) takes the form of the Wholer equation $(\log \mathrm{S}=\mathrm{a}-\mathrm{b} \log \mathrm{EN}) . \mathrm{In}[31]$ is explained the linear regression of the experimental data from [23] with the variables $\mathrm{S}$ and EN. From the regression analysis, the obtained parameters of the Weibull distribution (equation 3) for different values of S are presented in table 1 [31].

\begin{tabular}{|c|c|c|}
\hline $\mathbf{S}$ & $\mathbf{a}$ & $\mathbf{u}$ \\
\hline 0.9 & 0.8511 & 528 \\
0.8 & 0.5353 & 3436 \\
0.75 & 1.0753 & 1324 \\
0.70 & 0.4604 & 40306 \\
0.65 & 0.2379 & 40010 \\
0.60 & 0.4202 & 353144 \\
0.55 & 0.8785 & 29138 \\
\hline
\end{tabular}

Table 1.- Parameters a and $\mathrm{u}$ of Weibull distribution for different values of stress level $\mathrm{S}$

From table 1, it becomes clear that the hypothesis of constant value of deviation s ( or constant value of a ) for different stress levels is not valid. Based on these results, and the fatigue equation of the type:

$\mathrm{S}=\mathrm{A} \times \mathrm{N}^{-\mathrm{B}(1-\mathrm{R})}$

the values in table 2 are obtained for the coefficients A and B for different values of the survival function SF [31]

\begin{tabular}{|c|c|c|}
\hline SF & A & B \\
\hline 0.95 & 1.106 & 0.0998 \\
0.90 & 1.303 & 0.1109 \\
0.80 & 1.458 & 0.1095 \\
0.70 & 1.494 & 0.1023 \\
0.60 & 1.487 & 0.0945 \\
0.50 & 1.464 & 0.0874 \\
\hline
\end{tabular}

Table 2.- Parameters of fatigue equation(6) depending on the required confidence level

According to the values in table 2, the mean value of the coefficient B for SF>0.6 is 0.1034 . The proposed fatigue equation ( $\mathrm{S}-\mathrm{N}$ relation) for a survival probability of $95 \%$ for masonry in any condition (dry, wet or submerged) is:

$\mathrm{S}=1.106 \mathrm{~N}^{-0.1034(1-\mathrm{R})} \quad \mathrm{S}>0.5$

An endurance limit can be observed for $\mathrm{S}=0.5$

According to equation (7), the curves defining the fatigue equation for different confidence level in the S-N plane, are a set of parallel straight lines. In figure 6 are presented the experimental data (divided in dry, wet and submerged specimens and the 
run outs are also indicated) and the linear functions for a survival probability $\mathrm{SF}=0.95$ and 0.7 .

The parameters a and $\mathrm{u}$ in table 1, depending on the stress level, and coefficients $\mathrm{A}$ and $\mathrm{B}$ in table 2, depending on the confidence level, can be used for the reliability-based assessment to fatigue of existing masonry arches. In fact, as Roberts et al. point out in their paper [23], the low compressive strength of the brick and mortar used to manufacture the test specimens were intended to be representative of the type of bricks and mortar likely to be encountered in relatively old masonry arch bridges.

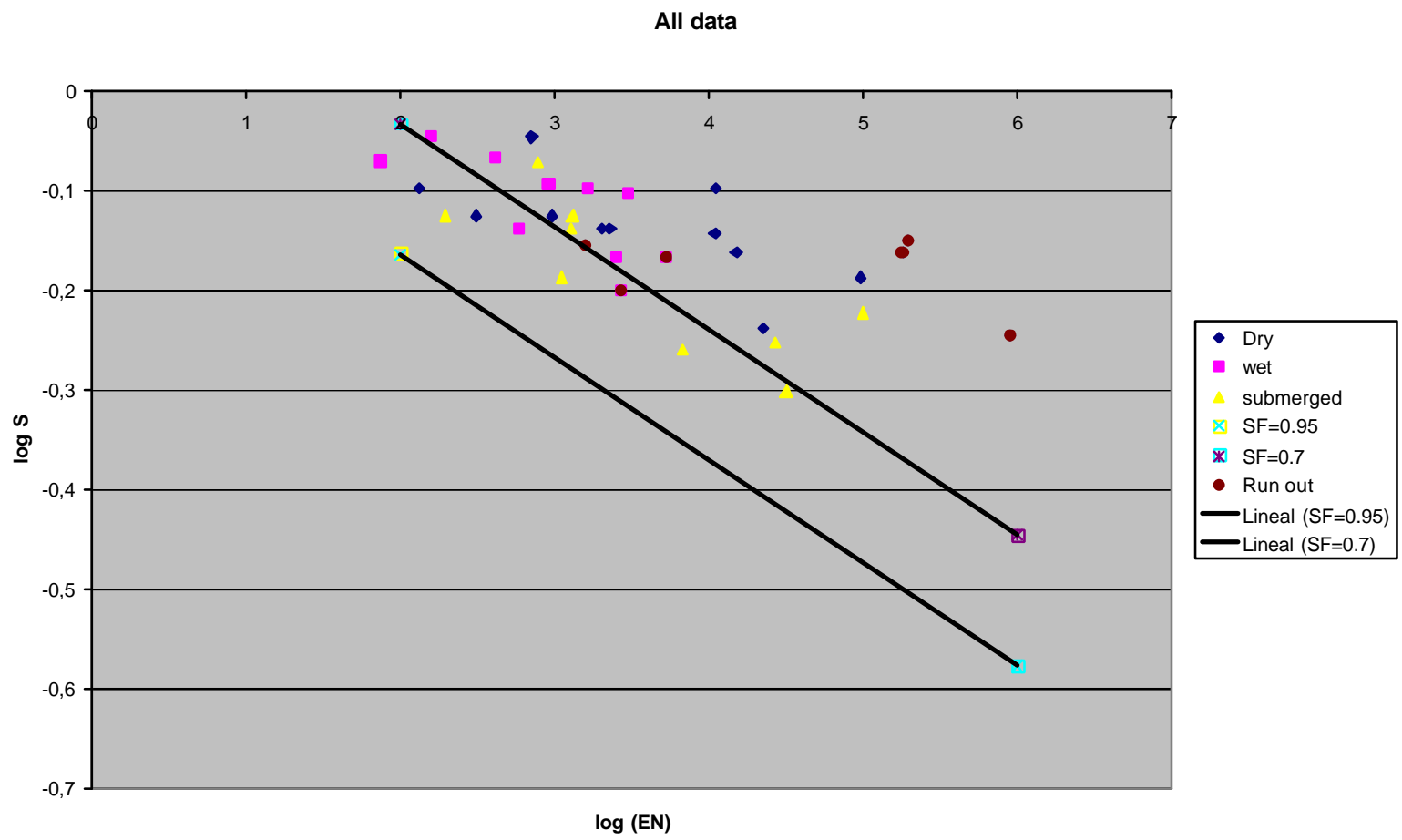

Figure 6.- Experimental data (all tests) and proposed fatigue equation for probability of failure of 5 and $30 \%$.

\subsection{2.- $S$ - $N$ diagrams for masonry in shear}

No experimental data from laboratory specimens is available at the moment to derive the corresponding $\mathrm{S}-\mathrm{N}$ relationships as for the case of masonry in compression. The only available data correspond to cyclic loading tests carried out at the University of Salford [4] in multi ring arches failing by ring separation (figure 3). This case may be considered as representative of the brick joints subjected to shear action. 


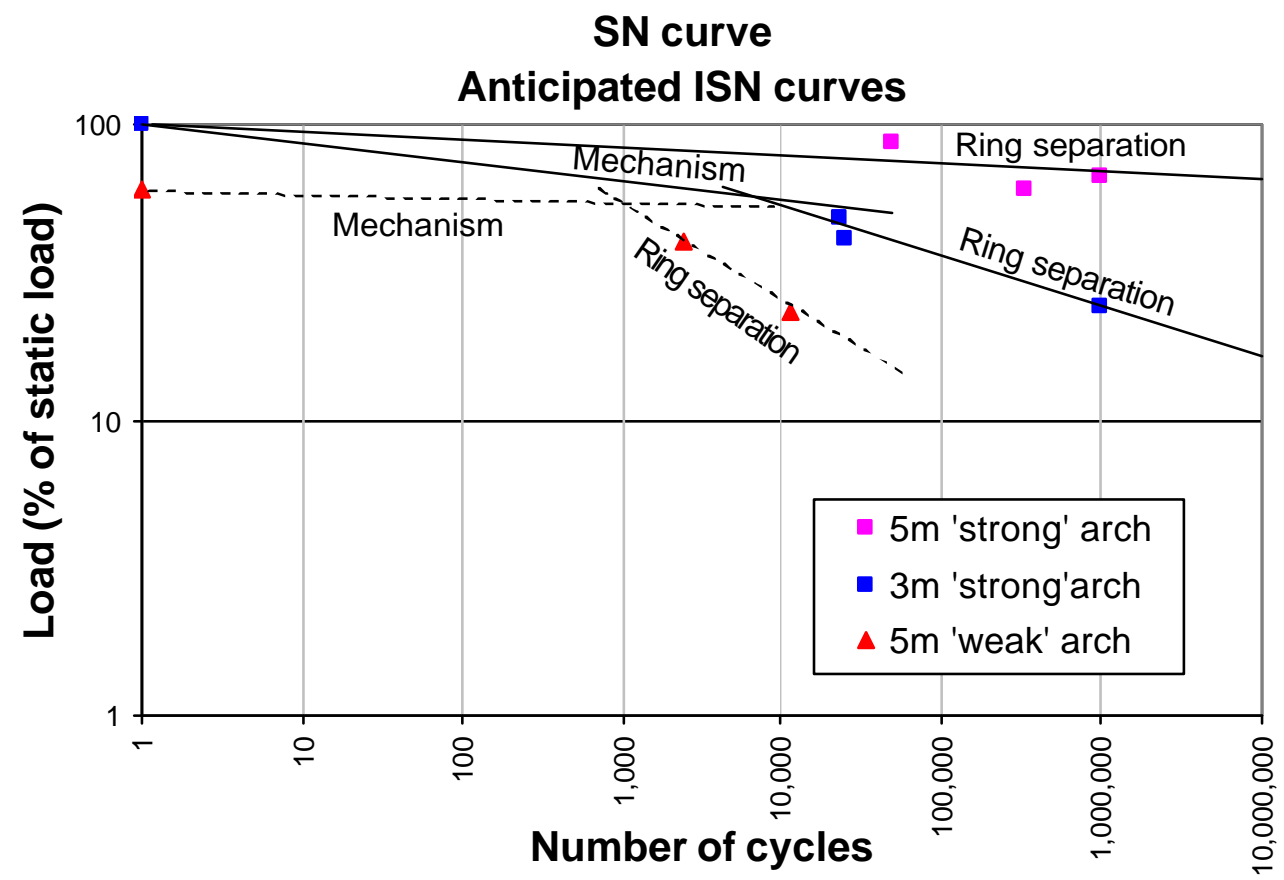

Figure 7.- Results of laboratory tests for high cycle loading [4]

Figure 7 is a summary of the results obtained in Salford's tests. As shown there, the fatigue mechanism of ring-separation can also be represented by a straight line in a $l o g$ $S$ versus $\log N$ diagram. The diagram in figure 7 was obtained from tests carried out in the whole arch (system failure) and not in small specimens (local failure). For this reason, despite the materials for the 5 and $3 \mathrm{~m}$ strong arches are the same, a different behaviour in fatigue is observed depending on the arch's span. The main difference between both arches is the span-length and, as a consequence, the stress level in the masonry for the case of self-weight plus permanent load (minimum stress) and the stress level due to the applied test load (maximum stress). As different stress le vels during the tests lead to different S-N diagrams, we may assume, as in the case of the masonry subjected to compression, a stress versus number of cycles to failure relationship in the form:

$\mathrm{S}=\mathrm{A} \mathrm{N}^{-\mathrm{B}(1-\mathrm{R})} \quad \mathrm{S}>0.4$

The two different straight lines in figure 7 for the strong brick and the $3 \mathrm{~m}$ and $5 \mathrm{~m}$ span can be, then, explained by a different value of $\mathrm{R}$ (stress minimum/stress maximum) in the tests in the 3 and $5 \mathrm{~m}$ span arches.

The results from the tests show and endurance limit around $40 \%$ of the maximum static load for $3 \mathrm{~m}$ span arches and good quality of brick. A similar endurance limit can be defined in the case of $5 \mathrm{~m}$ span arches made of weak brick.

Therefore, based on the very few data available, it seems that a similar format of the S$\mathrm{N}$ diagram can be assumed for the masonry in compression and in shear. Only the coefficients A and B will be different. The values of A and B have been derived in the previous chapter for fatigue of masonry in compression (see table 2). To obtain these coefficients in the case of shear, a set of tests similar to those reported in [23] can be designed, but where the predominant action is the shear stress in the mortar between bricks. The idea is to test small specimens and not complete arches as the last is much more difficult and expensive. Tests on a representative number of specimens will allow 
to define if a Weibull distribution also fits well the experimental results in this case, and to obtain the parameters of the distribution

Up to the moment when the results of the tests of masonry in shear may be available, the proposal is to use some rough estimates of parameters A and B based on the fatigue tests described in [4]. According to equation (8) and the experimental values shown in figure 7 , one may roughly assume the values $\mathrm{A}=2.69, \mathrm{~B}=0.3$ for the $3 \mathrm{~m}$ arch, and $\mathrm{A}=$ $1.20, \mathrm{~B}=0.11$ for the $5 \mathrm{~m}$ arch.

Taking into account the few experimental data available and until more experimental data is obtained, the fatigue equation proposed is:

$\mathrm{S}=2.69 \mathrm{~N}^{-0.3(1-\mathrm{R})} \quad \mathrm{S}>0.4$

The methodology to apply in the assessment of multi-ring arches to fatigue is similar to that proposed for single-ring arches. In this last case, it is necessary to have models to derive the compression in the most critical points of the arch as a function of time depending on the external variable actions. In the same way, in the former case, the availability of models to obtain the shear stresses in the contact between rings will be necessary to perform a service life analysis. However, because the actions due to the passage of the normal traffic will not cause a high stress level, even a linear-elastic model can be used to calculate the compression and shear stresses at defined critical points of the arch.

Depending on the span-length of the arch, the number of cycles of load to take into account will be the total number of axles or the total number of vehicles passing the bridge. The vibration amplitudes due to dynamic effects of the traffic loads will be very small for this type of bridges due to the damping through the infill, and, therefore, can be neglected in the calculation as they will be under the endurance limit.

\section{5.- Example}

\section{1.- Assessment of ULS by 4-hinges mechanism}

The example of application corresponds to the Magarola river bridge, located in Spain. A probabilistic capacity assessment was carried out, starting with the experimental testing program in order to get information about the geometric dimensions and the strength characteristics of the materials, as no documentation was available at all. This is normally the case of most existing masonry arches around the world.

\subsection{1.-Description of the bridge}

The Magarola bridge is located in Esparreguera, a city close to Barcelona (Catalonia, Spain), on the N-II highway and was built in the XIX Century. The bridge (Figure 8 ) is composed of five brick masonry barrel vaults spanning twenty meters each. The overall length of the structure is $160 \mathrm{~m}$ and its maximum height is $25 \mathrm{~m}$. The piers are built of rubble stone masonry reinforced with ashlars in their corners. The section of the piers is variable and measures $7 \times 3 \mathrm{~m}$ at the abutments of the arches. The condition assessment carried out before the capacity assessment concluded that the bridge is in good 
condition despite the enlargement of its roadway with a concrete slab made in 1990 that carries two lanes of traffic in one direction.

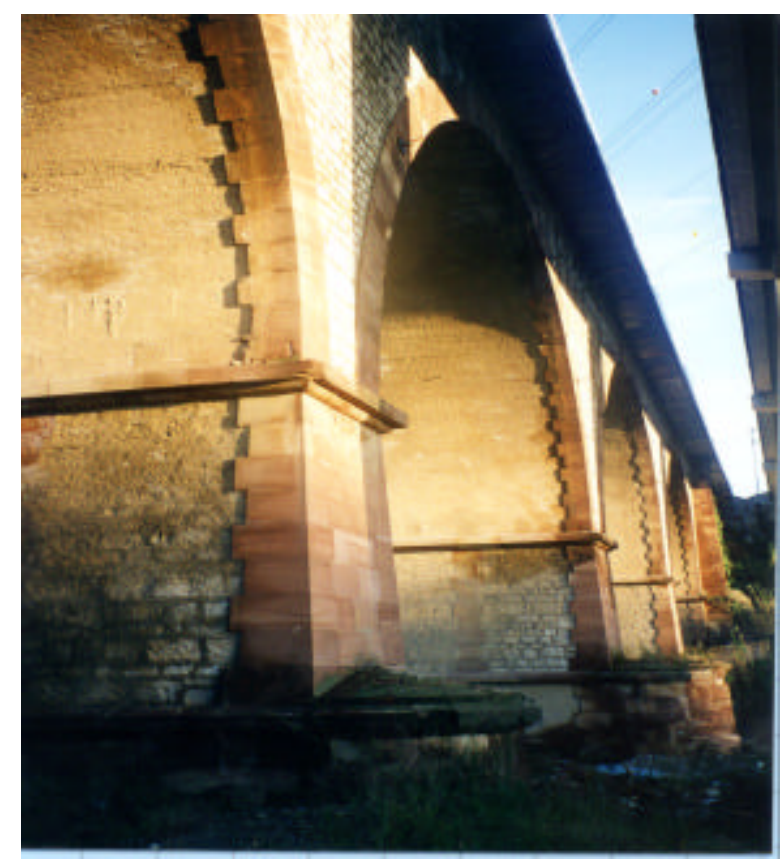

Figure 8.- Lateral view of the Magarola bridge

Because no drawings or other documentation was available, the main geometric parameters (cross section depth $\mathrm{H}$ and width $\mathrm{B}$ ) of the arches and the mechanical properties of the materials were derived from the tests as shown in Tables 3 and 4 . The shape of the arches was defined by obtaining the co-ordinates of twenty-one (21) points. This made possible to prove the exactitude of the semi-circumference they describe. The raise at mid-span was measured as $10 \mathrm{~m}$ and de depth of fill at crown $1.15 \mathrm{~m}$. Six vertical boreholes of $2.10 \mathrm{~m}$ to $2.25 \mathrm{~m}$ and four horizontal ones of 1.5 to $3.17 \mathrm{~m}$ allowed for recognition of the inside geometry of the bridge and its composition, and obtaining several cores to be tested in the laboratory. The infill material was classified as gravelly sand and brown clay. Some of the tested cores, which included brick and mortar joints, gave the information about the masonry's strength and the characteristics of the filling material. Horizontal boreholes detected concrete backing on the four piers.

\begin{tabular}{lll}
\multicolumn{1}{c}{ Arch ring } & & \\
Compressive Strength & Experimental & $15.0 \mathrm{MPa}$ \\
Deformation modulus & Assumed & $3000 \mathrm{MPa}$ \\
Tensile strength & Assumed & $0.01 \mathrm{MPa}$ \\
Density & Experimental & $1800 \mathrm{~kg} / \mathrm{m}^{3}$ \\
Fill & & \\
Compressive Strength & Experimental & $1.0 \mathrm{MPa}$ \\
Deformation modulus & Assumed & $30 \mathrm{MPa}$ \\
Density & Experimental & $2300 \mathrm{~kg} / \mathrm{m}^{3}$
\end{tabular}


Table 3.- Average material properties derived from the tests or assumed

\subsection{2.- Assessment assuming linear-elastic behaviour}

The bridge safety is first assessed according to the LS function in equation 4 . In table 4 are displayed the values obtained for $\mathrm{N}$ (axial compression) and $\mathrm{M}$ (bending moment) due to self-weight (sw), permanent load (pl) and traffic action (LL) at the most critical sections using a linear-elastic model.

\begin{tabular}{|l|l|l|l|l|}
\hline Variable & Mean & C.O.V. (\%) & Type \\
\hline $\mathrm{H}(\mathrm{m})$ & 1.11 & 10 & Normal \\
\hline $\mathrm{B}(\mathrm{m})$ & 7.0 & 5 & Normal \\
\hline $\mathrm{f}_{\mathrm{c}}(\mathrm{MPa})$ & 15.0 & 20 & Normal \\
\hline \multirow{3}{*}{$\mathrm{N}_{\mathrm{sw}+\mathrm{pl}}(\mathrm{kN})$} & 1 & 875 & 5 & Normal \\
\cline { 2 - 3 } & 2 & 3757 & & \\
\cline { 2 - 3 } & 3 & 3129 & & \\
\hline \multirow{3}{*}{$\mathrm{N}_{\mathrm{LL}}(\mathrm{kN})$} & 1 & 412 & \multirow{2}{*}{10} & Gumbel \\
\cline { 2 - 3 } & 2 & 324 & & \\
\cline { 2 - 3 } $\mathrm{M}_{\mathrm{sw}+\mathrm{pl}}$ & 3 & 500 & & \\
\cline { 2 - 3 }$(\mathrm{kNm})$ & 2 & 2580 & \multirow{2}{*}{5} & \\
\cline { 2 - 3 } & 3 & 598 & & \\
\cline { 2 - 3 } $\mathrm{M}_{\mathrm{LL}}(\mathrm{kNm})$ & 1 & 966 & & \\
\cline { 2 - 3 } & 2 & 804 & & \\
\cline { 2 - 3 } & 3 & 1099 & & \\
\hline
\end{tabular}

$\mathbf{1}=$ support of $\operatorname{arch} 1,2=$ quarter of $\operatorname{arch} 2, \mathbf{3}=$ midspan of $\operatorname{arch} 2$

Table 4.- Statistical definition of random variables

The actions due to the live load were obtained from a probabilistic model for traffic flow simulation that uses the influence lines of the effect under study [25].The values correspond to a period of 100 years. Using the FORM method [33] for the calculation of the reliability index $(\beta)$, the values obtained for the sections at support, quarter-span and mid-span are $\beta_{1}=1.65\left(\mathrm{P}_{\mathrm{f}}=0.49 \times 10^{-1}\right), \beta_{2}=4.82\left(\mathrm{P}_{\mathrm{f}}=0.79 \times 10^{-6}\right), \beta_{3}=1.14\left(\mathrm{P}_{\mathrm{f}}=0.127\right)$. From these low values of the reliability indices it is clear that the bridge safety is really low for the existing traffic on the bridge. However, the bridge is carrying the actual loads perfectly. The conclusion was then that the model does not accurately reflect the real behaviour. For this reason, the system reliability analysis was performed.

\subsection{3.- Assessment based on non-linear response and system failure analysis}

It is assumed in this case that, provided the ultimate strength of the material is not reached at any section, the bridge fails when a sufficient number of plastic hinges (normally 4) develop in different cross-sections. In this case, the Limit State Function can be written as:

$$
\mathrm{G}=\mathrm{R}-\mathrm{S}
$$

$\mathrm{R}$ is the ultimate resistance of the bridge taken as a system, i.e., the load that the bridge can carry up to the development of the failure mechanism. $\mathrm{S}$ is the external traffic action. In order to statistically characterize the random variable $\mathrm{R}$, a simulation process was carried out using a deterministic model for non linear- analysis of masonry structures up to failure $[21,34,35]$. Non-linear analysis of the structure under dead loads 
showed that the arch rings are quite uniformly compressed with the exception of a short zone at the extrados of the springings.

Performing a simulation process based on the Uptaded Latin Hypercube Method and using a Kolmogorov-Smirnof fitting technique, it was found that the load factor, $\lambda$, is well approximated by a Lognormal variable with mean equal to 56.7 and standard deviation 10.6 [12]. Fifty simulations were carried out where the failure mode was always the 4-hinge mechanism. The load factor $(\lambda)$ is defined as the value that applied to the axle loads of the average 5-axle truck $(400 \mathrm{kN})$ produces the failure of the arch. The surveyed traffic data with the distribution of total weight in 5-axle trucks, identified $\mathrm{S}$ as a Normal random variable with mean 2.0 (two 5 axle truck side by side) and a coefficient of variation (COV) equal to $25 \%$. According to these values, a reliability index $\beta=12.9$ was obtained for the actual traffic. As can be seen, the safety of the bridge using a reliability-based methodology with a suitable and accurate model of the bridge behaviour up to failure can be assured. Much higher reliability level is obtained compared to the linear analysis.

In conclusion, when a model that fully reflects the complex and non-linear behaviour of multi-span arch bridges is used, the corresponding reliability indices are high enough to assure the correct performance. Contrary, the assessment has also shown how assuming a simplified and not as accurate model, the corresponding results may be completely unrealistic and lead to inappropriate decisions concerning bridge safety. The non-linear model predicts a mechanism of collapse involving adjacent piers and arches. The analyses carried out also showed the importance of taking into account the complete structure instead of a single arch. In fact, the analysis for single arches would have produced an overestimation of $100 \%$ of the load capacity. These two conclusions are very important regarding the future assessment of other multi-span arch bridges

\section{2.- Fatigue assessment}

The assessment of the fatigue performance of a bridge can be formulated in two different ways:

1.- Calculation of the reliability index or probability of failure in a given reference time

2.- Calculation of the remaining service life with a predefined probability level.

With the available experimental data, the first assessment will be only pertinent in the case of fatigue due to compression in the masonry (single-ring arches). The process of the calculation of the reliability index or probability of failure due to service loads causing a fatigue failure is as follows:

1.- Build up a theoretical model of the bridge. Because the load level introduced in the analysis will be equivalent to the service loads, a linear elastic model or other simplified models can be used.

2.- Define the typical live load events in the bridge that may create stresses relevant to fatigue damage. Define how many of each live loading scenario will happen in the remaining service life period according to the traffic conditions.

3.- Simulate the passage of each live load event in the numerical model and obtain the stress versus time relationship for the most critical locations in the bridge. Take into account that the loads should include the dynamic amplification factor (if relevant) as we are dealing with service load levels.

4.- From the stress-time relationship obtain the maximum stress in the predefined locations and obtain the relation $S=$ maximum stress/ compressive strength for each 
load scenario and only for the stress peaks in the stress-time curve where $S>0.5$ (endurance limit)

5.- For each value of $S_{i}>0.5$ and according to the number of loading events that will cross the bridge in the defined period of time, obtain the number of times, $n_{i}$, that each value $S$ will be reached in the selected locations ( Define the histogram of $S$ ).

According to what is explained in the next point, it is recommended to obtain the values of $\mathrm{n}_{\mathrm{i}}$ for the ranges $0.5<\mathrm{S}<0.55,0.55<\mathrm{S}<0.6,0.6<\mathrm{S}<0.65,0.65<\mathrm{S}<0.7$, $0.7<\mathrm{S}<0.75,0.75<\mathrm{S}<0.8,0.8<\mathrm{S}$.

6.- According to the Miner's rule, the limit state function can be defined as:

$$
G=1-\sum_{S_{i}>0.5} \frac{n_{i}}{N_{i}}
$$

where $\mathrm{N}_{\mathrm{i}}$ is the number of loading events causing the failure. According to what is explained in previous chapters, $\mathrm{EN}_{\mathrm{i}}=\mathrm{N}_{\mathrm{i}}^{(1-\mathrm{R})}$ is a random variable that can be modelled by a Weibull distribution with the parameters as presented in table 5 depending on the value of $S$. The ranges of $S$ and the parameters in table 5 are defined according to the results shown in table 1 . The upper value of the range has been assigned to the whole range. For each of the 7 ranges of $S$ defined in point 5 , the corresponding parameters of the distribution can be obtained from table 5 .

\begin{tabular}{|c|c|c|}
\hline $\mathbf{S}$ & $\mathbf{a}$ & $\mathbf{u}$ \\
\hline$>0.8$ & 0.8511 & 528 \\
$0.75-0.8$ & 0.5353 & 3436 \\
$0.70-0.75$ & 1.0753 & 1324 \\
$0.65-0.70$ & 0.4604 & 40306 \\
$0.60-0.65$ & 0.2379 & 40010 \\
$0.55-0.60$ & 0.4202 & 353144 \\
$0.5-0.55$ & 0.8785 & 29138 \\
\hline
\end{tabular}

Table 5.- Parameters of the Weibull distribution $(\mathrm{EN})$ as a function of the stress level

7.- Once the random variables $\mathrm{EN}_{\mathrm{i}}$ and consequently $\mathrm{N}_{\mathrm{i}}$ present in the limit state function are perfectly defined, then applying FORM, the reliability index can be calculated.

For the bridge in the example (Magarola bridge), the maximum stresses in the critical sections of the bridge are due to the passage of two side by side 5-axle trucks. The maximum stress (permanent loads + live load including an impact factor equal to 1.15) is $2.5 \mathrm{MPa}$ only. Therefore $\mathrm{S}=2.5 / 15=0.17$ is quite below the endurance limit $(\mathrm{S}=0.5)$ and therefore, no fatigue problems are foreseen.

\subsection{1.- Sensitivity analysis}

As shown before, the bridge in the actual condition is fatigue safe. Let us assume now that over time, due to deterioration problems in the bricks at one of the pier supports, the compressive strength of the masonry decreases from 15 to $4.5 \mathrm{MPa}$. Now $\mathrm{S}=$ $2.5 / 4.5=0.56$ and therefore a fatigue verification is needed. The application of steps 1 to 7 will be as follows:

1.- The same model used in 5.1.2 is adopted here 
2.- According to the traffic characteristics in the bridge site, only the 5-axle trucks produce in the support of the bridge stresses that are significant. The average daily traffic in the bridge is 15000 vehicles and $20 \%$ are 5-axle trucks. The number of daily events involving two 5 -axle truck side by side is estimated in 200 . The number of daily events involving one 5 -axle truck is 2600 .

3.- For the load event of a single 5-axle truck in the bridge the maximum stress is 2.2 $\mathrm{MPa}$. For two 5-axle trucks side by side the maximum stress is $2.5 \mathrm{MPa}$.

4.- In the first case $S=2.2 / 4.5=0.49<0.5$ that is below the endurance limit. Therefore only the second live load event should be considered in the fatigue check.

5.- The number of events, $n$, in the range $0.55<\mathrm{S}<0.6$ for a period of 50 years is $200 \mathrm{x}$ $365 \times 50=3,650,000$ load events. The stress due to self- weight and permanent loads is 1.9 $\mathrm{MPa}$. Therefore, for this load event $\mathrm{R}=1.9 / 2.5=0.76$

6.- The Limit State function is:

$$
G=1-\frac{3.65 \times 10^{6}}{N}=1-\frac{3.65 \times 10^{6}}{E N^{\frac{1}{1-R}}}
$$

where $\mathrm{EN}$ is a random variable with a Weibull distribution with parameters $\mathrm{a}=0.42, \mathrm{u}$ $=353144$

7.- In this case with only 1 random variable in the LS function the calculation of the probability of failure is immediate and does not require the application of FORM or similar

$$
P_{f}=P[G<0]=P\left[E N<\left(3.65 \times 10^{6}\right)^{1-0.76}\right]=1-\exp \left[-\left(\frac{\left(3.65 \times 10^{6}\right)^{0.24}}{353144}\right)^{0.42}\right]=0.021
$$

For the sake of simplicity in this example, the weight of the truck has been considered deterministic. In the case that the randomness in the truck weight was assumed, then the number of events "n" would become a random variable that could be statistically defined from the histogram of truck weight. Therefore, in this case, the histogram of truck weight will be necessary ( can be obtained using Weigh-in-Motion techniques ) and then the calculation of the reliability index would need the use of a FORM algorithm or similar.

The process of the calculation of the remaining service life with a predefined probability level is as follows:

1.- Proceed from step 1 to five as in the previous case

The same case with a compressive strength of the masonry equal to $4.5 \mathrm{MPa}$ will be considered. The only event causing maximum stresses above the endurance limit is the passage of two 5-axle truck side by side. The corresponding maximum stress associated to this event is $2.5 \mathrm{MPa}$ and, therefore, $\mathrm{S}=2.5 / 4.5=0.56$

2.- Calculate the minimum stress level (compression or shear) in the selected locations. This will be the value corresponding to the empty bridge (self- weight + permanent loads). For each stress range, calculate the ration $\mathrm{R}_{\mathrm{i}}=$ minimum stress/maximum stress 
For the example, as there is only one stress range to consider, then $\mathrm{R}=1.9 / 2.5=0.76$

3.- In the case of fatigue due to compression (single-ring arches), according to equation

(6) and the values of A and B in table 2 for the desired confidence level, calculate for each range of $\mathrm{S}$ (with the corresponding values of $\mathrm{R}$ ) the number of events to failure $\mathrm{N}_{\mathrm{i}}$ From equation (6) and table 2 for a confidence level of $95 \%$ and according to the values obtained in steps 1 and 2, we have: $0.56=1.106 \times \mathrm{N}^{-0.0998(1-0.76)}$ and, consequently, $\mathrm{N}=2.07 \times 10^{12}$

4.- In the case of fatigue due to shear (multi-ring arches), at this moment the only fatigue equation available is equation (9), which corresponds to a probability of $50 \%$ (correlated directly to test data). Using this equation, the number of events to failure $\mathrm{N}_{\mathrm{i}}$ can be estimated.

In this case, being a single-ring arch, this is not necessary.

5.- Given the estimated number of load events crossing the bridge for a reference period ( 1 year for instance), then calculate the time necessary to reach the value 1 in the expression of accumulated damage.

In 1 year, the number of load events is $200 \times 365=73,000$ and, the remaining fatigue life with a confidence level of $95 \%$ is $2.8 \times 10^{7}$ years.

\section{6.- Conclusions}

The paper reports the feasibility of the application of probabilistic techniques to the assessment of existing masonry arches. A state-of-the-art on the failure modes and structural behaviour of such bridges under low and high load levels was elaborated. The proposal of a reliability-based format for the assessment of masonry arch bridges has been derived. The following conclusions can be drawn:

1.- Probabilistic assessment methods are not generally used for masonry arch bridges. One of the reasons of its limited application is the difficulty of defining reliable failure criteria for these types of structures. Experimental tests have shown that failure of an arch is generally of a global nature rather than by failure of individual components. There is also a lack of accurate theoretical models to idealise the behaviour of masonry arch bridges as a system. The example shown evidences the importance of accurate models to obtain reliable results. The need of simple numerical models to perform fast simulation trials has been enhanced. Thus, the influence of important features in the bridge response, as the arch-backfill interaction, the modelling of multi-ring arches and the bridge skew in the development of simplified theoretical models at the ultimate and serviceability limit states should be worked out too.

2.- Different failure modes and hence different limit state functions are possible in masonry arch bridges. The global failure of the arch due to the formation of a hinged mechanism has been the only failure mode considered so far. However, other response mechanisms (ring separation, material crushing,...) may lead the masonry arch to the failure. The serviceability issues related to the fatigue behaviour under service loads should be also considered, as they appear also to play an important role in the service life of existing masonry arches. Thus,a probabilistic approach to the 4-hinges mechanism as well as to the fatigue failure assessment of masonry arch bridges have been also derived. 
3.- A methodology is presented for the fatigue and serviceability assessment of masonry arches, and probabilistic S-N curves, based on Weibull distributions, for the behaviour of masonry under fatigue are developed based on the few experimental data available. In the case of masonry under compression, a fatigue equation with various levels of confidence is also proposed that may be used for deterministic assessments. In the case of masonry under shear, a fatigue equation with a $50 \%$ confidence level is also proposed. The last can be of relevant application to the case of multi-ring arches.

4.- The assessment methodology developed can be considered as complete. However, due to the lack of experimental data (mainly on material properties and fatigue due to shear ) the practical application to existing bridges should still be looked as preliminary and the results taken with caution. The preliminary models available today have to be updated as more experimental data becomes available from future laboratory and fullscale tests.

\section{7.- Acknowledgements}

The author wishes to thank the European Community's Sixth Framework Programme by the funding received through Research Projects "Sustainable Bridges" and "ARCHES", as well as to the Spanish Ministry of Education by funding of Research Projects BIA-2006-15471-C02-01 and BIA-2007-28685-E.

\section{8.- References}

[1] Pippard AJS, Chitty L. A study of the voussoir arch. National Building Series. Research Paper 11, London, 1951

[2] Heyman J. The masonry arch. Ellis Horwood Ltd. Chichester,1982

[3] Page J. Masonry arch bridges. State of the art review. Transport Research Laboratory. Department of transport, London, 1993.

[4] SB4.7 Structural assessment of masonry arch bridges. Background document. Prepared by Sustainable Bridges- a project within EU FP6. Available from: www.sustainablebridges.net [cited 30 November 2007]

[5] Melbourne C,Tomor AK. A new assessment method for masonry arch bridges. In: Bridge Maintenance, Safety, Management, Life-Cycle Performance and Cost, Proceedings of IABMAS'06, Porto, 2006, p. 747-748

[6] Melbourne C, Wang J, Tomor AK. A new masonry arch bridge assessment strategy (SMART). Proceedings of the Institution of Civil Engineers. Bridge Engineering, 2007; 160 BE2: 81-87

[7] Lauridsen J, Jensen JS, Enevoldsen I. Bridge owner's benefits from probabilistic approaches. Structure and Infrastructure Engineering, 2007; 3 (4): 281-302

[8] Enevoldsen, I. Experience with probabilistic-based assessment of Bridges. Structural Enginnering International, 2001; 11 (4): 238-246 
[9] Lauridsen J, Bjerrum J,O’Connor AJ, Enevoldsen I. Experience with probabilitybased assessment of bridges based upon the Danish Guideline. In: Bridge Maintenance, Safety, Management, Life-Cycle Performance and Cost, Proceedings of IABMAS'06, Porto, 2006, p. 509-511

[10] Wisniewski D, Casas JR, Ghosn M. Simplified probabilistic non-linear assessment of existing railway bridges. Structure and Infrastructure Engineering. In press. DOI: $10.1080 / 1573247070 / 639906$

[11] Wisniewski D, Casas JR, Ghosn M. Load-capacity evaluation of existing railway bridges based on robustness quantification". Structural Engineering International, 2006; 16 (2): 161-166.

[12] Casas JR. Permit vehicle routing using reliability-based evaluation procedures. Transportation Research Record, 2000; 1696 (2): 150-157.

[13] Sykora M, Holicky M. Probabilistic model for masonry strength of existing structures. Engineering Mechanics, 2010; 17(1): 61-70

[14] Mojsilovic N, Faber M H. Probabilistic assessment of masonry compressive strength. In: Proc. of ICOSSAR 2009, Osaka (Japan), 2009

[15] Ellingwood B. Analysis of reliability for masonry structures. Journal of the Structural Division, ASCE, 1981, 107(5): 757-773

[16] Schueremans L, Van Gemert D. Reliability analysis in structural masonry engineering, In: Proc. of IABSE Colloquium "Saving Buildings in Central and Eastern Europe, Berlin (Germany), 1998.

[17] Stewart MG, Lawrence S. Structural Reliability of masonry walls in flexure. Masonry International, 2002; 15 (2): 48-52

[18] Stewart MG, Lawrence S. Model error, structural reliability and partial safety factors for structural masonry in compression. Masonry International, 2007; 20(3): 107116

[19] Zhai X, Stewart MG. Structural reliability analysis of reinforced grouted concrete block masonry walls in compression. Engineering Structures, 2010; 32: 106-114

[20] Schueremans L. Probabilistic evaluation of structural unreinforced masonry. Ph.D. Thesis. Katholieke Universiteit Leuven, 2001.

[21] Casas JR. Assessment of masonry arch bridges. Experiences from recent case studies. In: Current and future trends in bridge design, construction and maintenance. Thomas Telford, 1999, p. 575-586

[22] Audenaert A, Peremans H, Reniers G. An analytical model to determine the ultimate load on masonry arch bridges. J Eng Math, 2007; 59: 323-336 
[23] Roberts TM, Hughes TG, Dandamudi VR, Bell B.Quasi-static and high cycle fatigue strength of brick masonry. Construction and Building Materials, 2006; 20: 603614

[24] Crespo-Minguillon C, Casas JR. Fatigue reliability analysis of prestressed concrete briges. Journal of Structural Engineering, ASCE, 1998; 124(12): 1458-1466

[25] Crespo C, Casas JR. A comprehensive traffic load model for bridge safety checking, Structural Safety, 1997; 19(4):339-359.

[26] ASCE. Foreword to Fatigue and Fracture Reliability. A state of the Art Review . Journal of the Structural Division ASCE, 1982; 108: 1-88.

[27] Hwan B. Fatigue analysis of Plain concrete in Flexure. Journal of Structural Engineering, ASCE, 1986; 112 (2): 273-289.

[28] Shi XP, Fwa TF, Tan SA. Flexural fatigue strength of plain concrete. ACI Materials Journal, 1993; 90 (5): 435-440

[29] Castillo E, Fernández-Canteli A. Statistical models for fatigue analysis of long elements. In: Proceedings of the IABSE Workshop on Length Effect on Fatigue of Wires and Strands, El Paular, Madrid, 1992, p. 15-32.

[30] Fernández-Canteli A., Castillo E, Argüelles A. Length effect on fatigue of wires and prestressing steels. In: Proceedings of the IABSE Workshop on Length Effect on Fatigue of Wires and Strands, El Paular, Madrid, 1992, p. 125-135.

[31] Casas, J.R. A probabilistic fatigue strength model for brick masonry under compression. Construction and Building Materials, 2009; 23: 2964-2972

[32] D4.4.3. Probabilistic non-linear analysis. Background document. Prepared by Sustainable Bridges- a project within EU FP6. Available from: www.sustainablebridges.net [cited 30 November 2007].

[33] Melchers R.E. Structural reliability. Analysis and Prediction. Second Edition. John Wiley and Sons, New York, 1999.

[34] Casas JR, Molins C. Assessment of the Magarola arch bridge. A case study. In: Proceedings of the Sixth International Conference on Structural Studies, Repairs and Maintenance of Historical Buildings, Dresden, 1999, p. 333-342

[35] Molins C, Roca P. Capacity of masonry arches and spatial structures. Journal of Structural Engineering, ASCE, 1998; 124 (6): 653-663 